\title{
ALGUNS ASPECTOS DA CADEIA PRODUTIVA PESCADO ARTESANAL NA REGIÃO LINDEIRA AO ESTUÁRIO DA BAIXADA SANTISTA/SP
}

Wilson Moreira Junior ${ }^{1}$

RESUMO: Este texto contribui com informações sobre os pescadores artesanais da Baixada Santista/SP, ao tratar da cadeia produtiva do pescado de quatro comunidades, são elas: Sítio Conceiçãozinha, Sítio Cachoeira, Ilha Diana, Vila dos Pescadores. O pescador pode apresentar uma ou diferentes maneiras de escoar sua produção que pode permanecer a mesma, pode transformar-se e, ainda, coexistir simultaneamente ou por um período de tempo e, até mesmo, ao longo da vida. A cadeia produtiva não é estática, ocorrem variações por época do ano, tipo de recurso e oportunidades que aparecem ao longo da vida. O escoamento da produção identificado foi: consumo familiar; doação; escambo; comércio e perdas. Os pescadores apresentaram grande diversidade e adaptabilidade de inserção na cadeia produtiva.

Palavras-chave: Cadeia produtiva. Pesca artesanal. Baixada Santista.

\section{INTRODUÇÃO}

O escoamento de pescado é elemento revelador da estrutura das relações de produção, porém, não tem traços exclusivos ou estáticos dentro da comunidade e com seus interlocutores. Os grupos apresentam formas diversificadas de escoar a produção,

\footnotetext{
${ }^{1}$ Biólogo. UNESP.wilmorjr@hotmail.com
} 
estas não são estanques e podem permanecer estáveis, ou alternarem ou coexistirem entre si. A cadeia produtiva do pescado, além de dar indicações preciosas sobre a estrutura de produção da comunidade, também, indica como esta se relaciona com outros setores da sociedade.

Segundo SILVA (2005) a cadeia produtiva pode ser entendida de forma simplificada como um conjunto de elementos que podem ser empresas ou sistemas que interagem no processo produtivo com a finalidade de ofertar produtos ou serviços ao mercado consumidor. O sistema é um conjunto de elementos que se relacionam de acordo com uma lógica com o intuito de alcançar objetivos previamente estabelecidos. Para GEREFFI \& KORZENIEWICS (1996) a cadeia produtiva se dá como uma rede de trabalho e processo produtivo que visa à produção de uma mercadoria.

A cadeia produtiva é um conjunto de ações e atores que interagem entre si compondo-se do sistema produtivo, dos fornecedores de insumo e serviços, das indústrias de processamento, distribuidores, comerciantes e consumidores. Estes atores se relacionam entre si dentro de uma lógica que se organiza cronologicamente e segue um fluxo de etapas, no qual pode-se considerar que o produto ou o serviço tenham um início de sua preparação até o seu desfecho final que é quando chega ao consumidor. A dinâmica do produto (ou serviço) pode ser representada com o seguinte fluxo: insumos produção - processamento - comércio atacadista - comércio varejista - consumidor. Isto faz com que haja um fluxo inverso que é o de capital, que ocorre da seguinte forma: consumidor - comércio varejista - comércio atacadista - processamento - produção insumo. Estes são influenciados pelos ambientes institucionais e organizacionais (CASTRO et. al., 1995; SILVA, 2005).

De acordo com SCHULTZ (2001), a cadeia produtiva de produtos vegetais pode ser compreendida como a ligação e inter-relação de diferentes elementos que seguem uma lógica de oferta no mercado de commodities agrícolas in natural ou beneficiada. Com base neste contexto, Silva (2005) escreve que a Empresa Brasileira de Pesquisa Agropecuária - EMBRAPA adota uma metodologia composta por um sistema constituído basicamente por cinco atores, são eles: 
a) Fornecedores de insumo: são as empresas que ofertam produtos tais como: sementes, calcário, adubos, herbicidas, fungicidas, máquinas implementos agrícolas e tecnológicos;

b) Agricultores: são os segmentos que usam a terra para a produção de commodities, como a madeira, cereais e oleaginosas. Estas produções são realizadas em sistemas produtivos tipo fazenda, sítios ou granjas;

c) Processadores: são as agroindústrias que pré-beneficiam, beneficiam ou transformam os produtos in natura, como, por exemplo, as de prébeneficiamento que limpam, secam e armazenam grãos; beneficiamento que padronizam, beneficiam e empacotam produtos como arroz, amendoim, feijão etc.; as indústrias de transformação que processam uma determinada matéria prima e a transformam em um produto para comercializar, como o óleo de soja, cereal matinal, polvilho entre outros;

d) Comerciantes: são os atacadistas, os grandes distribuidores de produtos das redes de supermercados, postos de venda e mercados exteriores. Enquanto os varejistas são aqueles comerciantes junto aos consumidores finais.

e) Mercado consumidor: é o elo final da cadeia produtiva, constituído por grupos de consumidores, estes podem ser o mercado nacional ou o internacional.

Os diferentes segmentos da cadeia produtiva são influenciados e, até mesmo, em alguns pontos condicionados aos ambientes institucionais e organizacionais. Os institucionais são: as leis ambientais, trabalhistas, tributários, comerciais, de saúde, as normas, resoluções, instituições normativas e os padrões de comercialização, etc. Já o ambiente organizacional compõem-se de instituições governamentais, financeiras, empresas de pesquisa, agências credenciadas, entre outros (SILVA, 2005; CASTRO et al., 1995; ZYLBERSZTAJN, 1994).

Com base no exposto assume-se neste trabalho que a cadeia produtiva da pesca artesanal é um conjunto formado por ações e agentes que estão entre si relacionados com a produção do pescado que consiste da captura e suas diferentes etapas até chegar ao consumidor final. Estas podem ser as mais simples como a da captura manual para o 
próprio consumo até as mais complexas, nas quais as estratégias de pesca se utilizam de artes em que os equipamentos têm origem industrial e a produção passa por uma extensa rede de processamento, distribuição, comercialização até chegar ao consumidor final, nas mais diferentes regiões do Brasil e do mundo.

O presente artigo tem como objetivo abordar e descrever, brevemente, os diferentes elos da cadeia produtiva do pescado originário da pesca artesanal na Baixada Santista e demonstrar sua versatilidade em ambientes de grandes conflitos sociais e ambientais.

\section{MATERIAIS E MÉTODO}

Para esta pesquisa tomou-se como base quatro comunidades de pescadores artesanais, caiçaras e moradores ribeirinhos, do estuário da Baixada Santista, SP, em que a pesca artesanal era uma importante atividade econômica, cultural e de identidade, são

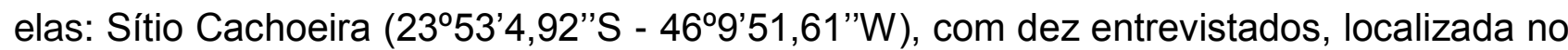

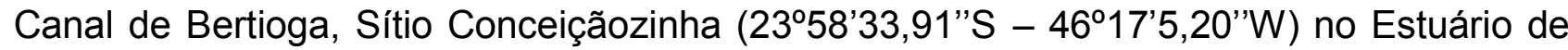
Santos, com onze entrevistados, ambas pertencentes ao município de Guarujá; a llha

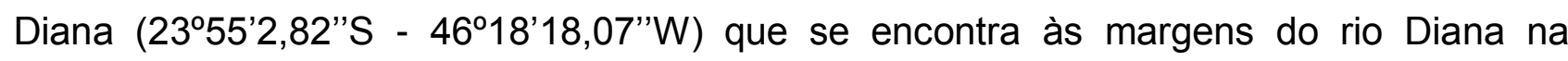
confluência do Canal de Bertioga com o Estuário de Santos no município de Santos, com

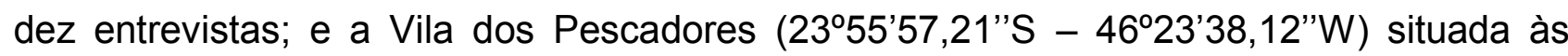
margens do rio Casqueiro, em Cubatão, com treze entrevistas.

Essas comunidades foram eleitas, para a presente pesquisa, por se localizarem em pontos distintos do estuário com diferentes conflitos socioambientais.

Para esta pesquisa utilizou como base entrevistas não-estruturada e semiestruturadas com perguntas abertas, além de depoimentos orais de pescadores, caiçaras e moradores ribeirinhos, preferencialmente àqueles reconhecidos pela comunidade que são conhecedores sobre os temas tratados da região do estuário de Santos, SP. As informações das entrevistas foram confrontadas com dados secundários disponíveis nas 
bibliografias referentes à pesca artesanal, populações tradicionais, caracterização da região da Baixada Santista, cadeia produtiva do pescado e sobre os impactos ambientais.

De posse dos depoimentos orais, do levantamento e análise da bibliografia, dos relatórios técnicos e outros documentos, pretendeu-se obter suas transformações e as respostas que as populações tradicionais dão aos impactos existentes.

\section{RESULTADOS E DISCUSSÃO}

\subsection{COMPONENTES DA CADEIA PRODUTIVA}

As comunidades de pescadores artesanais mantêm diferentes relações sociais, econômicas e produtivas diferentes da agricultura, em especial a agricultura de grande escala voltada para fornecer matéria prima para a indústria e a exportação. Essas relações também são diferentes da pesca industrial que objetiva capturar grandes quantidades de pescado para abastecer mercados consumidores muitas vezes distantes, através de uma complexa logística de transporte, industrialização, comércio e exportação.

O pescador artesanal dispõe de poucos recursos materiais para a captura, transporte, armazenamento e comércio da produção. Diferentemente da pesca industrial que dispõe de uma infra-estrutura e logística, que possibilita às vezes atuar em diferentes elos da cadeia produtiva do pescado e ocorrem casos que grupos empresariais dominam toda a cadeia. A atuação dessas empresas é gerenciada por técnicos burocratas que as administram, sem conhecer muitas vezes todo o processo, pois as atividades são desenvolvidas separadas e as tarefas referentes a elas feitas por grupos de trabalho diferenciados (DIEGUES, 1983; MALDONADO, 1985).

$\mathrm{Na}$ pesca industrial o pescador torna-se um proletário e participa somente da captura do pescado em tripulações nas quais as funções são compartimentadas com grande especialização das tarefas. Ele perde o poder de decisão que é exercido no escritório da empresa, que se organiza em diversos setores e integra-se verticalmente, nas funções de captura, processamento e comercialização. Na pesca artesanal, o 
pescado pertence ao pescador e é ele quem decide seu futuro, enquanto na pesca industrial a produção pertence à empresa, que é quem toma as decisões (DIEGUES, 1983; MALDONADO, 1985).

A seguir discutir-se-á a cadeia produtiva do pescado artesanal, com base nos depoimentos recolhidos e, em seguida, abordar-se-á a inserção do pescador na cadeia produtiva em diferentes elos.

Tomando como referência o método composto basicamente por cinco segmentos adotados pela EMBRAPA (SILVA, 2005) apresentada anteriormente, descrever-se-á a cadeia produtiva da pesca artesanal na Baixada Santista, que são os fornecedores de insumos, os pescadores, os fornecedores, comerciantes e mercado consumidor.

\subsubsection{FORNECEDORES DE INSUMOS}

São constituídos de empresas, comerciantes, atravessadores e artesãos que fornecem os produtos necessários a pesca, armazenamento, transporte, processamento e comércio que o pescador artesanal e o núcleo familiar e comunitário necessitam para fazer a produção e seu escoamento.

O pescado tende a deteriorar-se rapidamente após ser retirado de seu ambiente, o método mais comum para conservá-lo em boas condições para consumo é deixá-lo em uma temperatura que retarde a ação microbiológica e enzimática que atua em sua deterioração, para isso faz-se uso da "cadeia do frio", que consiste em deixá-lo a baixas temperaturas com o intuito de preservá-lo. Dessa forma, os pescadores necessitam comprar gelo nos entrepostos e indústrias pesqueiras na região, principalmente, aqueles que saem para pescar e ficam mais de um dia fora, nesses casos o gelo torna-se essencial. Nas últimas duas décadas, alguns pescadores compram freezer e geladeiras para conservar o pescado em suas residências até o momento da venda ou consumo. No passado quando os pescadores do Sítio Cachoeira tinham acesso às praias de sua região, eles usavam, também, o sal para conservar o pescado, porém, após o fechamento 
das praias pelos condomínios de luxo a técnica de salga com secagem ao sol para a conservação deixou de existir.

A captura na região é feita manualmente e com técnicas passivas e ativas que necessitam de diferentes apetrechos. No passado pescadores confeccionavam com linha de pesca e fios para tecerem a rede com tucum, conhecimento herdado dos índios. Mas, na primeira metade do século XX já era utilizado linhas de algodão industrializadas e que foram substituídas nas décadas de 1960 e 1970 por linhas de nylon, adquiridas no comércio local ou através de atravessadores e comerciantes que financiavam as redes em troca da fidelidade na venda da produção, o que muitas vezes era feito a preços irrisórios. Constatou-se que atualmente os fios de nylon, as linhas de pesca e as redes são adquiridas no comércio local. Há, também, pescadores especializados em confeccionar rede, comprando as linhas, chumbadas e bóias. No final da década de 1990 alguns pescadores do Sítio Conceiçãozinha começaram a tecer redes com cordone, inseriram, assim mais uma opção de matéria prima para confeccionar rede.

Até meados do século $X X$ predominava na região as canoas a remo utilizadas na pesca e no transporte regional, porém com a escassez de árvores adequadas e posteriormente as restrições legais para o corte esse tipo de embarcação rareou e hoje estão quase extintas. Essas canoas eram feitas por artesãos especializados da própria Baixada Santista ou encomendadas a mestres canoeiros de outros pontos do litoral. Havia, também, barcos pesqueiros como as traineiras que adquiriam canoas novas e usadas nos litorais paulista fluminense, paranaense e catarinense e revendiam em Santos, geralmente, o local dessas transações era o Mercado Municipal. A partir da década de 1950, começou a tomar lugar das canoas às chatas de madeira, que são barcos construídos por carpinteiros locais feitos de tabuas, chegava ao fim a era das canoas.

A partir da década de 1970, além das chatas começou a se disseminar barcos de madeira equipados com motor de centro, movidos a óleo diesel. No início da década de 1990, influenciados por comerciantes locais, bancos e agências de crédito vários pescadores adquiriram barcos de alumínio com propulsão de motor de popa a gasolina. 
Porém, os custos de manutenção desses motores e o consumo de combustível são bem mais elevados do que os motores de centro, juntamente com o fato de que esses barcos são inapropriados para exercerem alguns tipos de pesca fez com que os pescadores perdessem logo o interesse por essas embarcações. Esses barcos exigem que os pescadores aumentem o esforço de pesca para conseguir mantê-lo, com o colapso da pesca estuarina dos anos 1990 ficou muito difícil manter esses barcos na pesca artesanal. Muitos que não conseguiram saudar seus financiamentos perderam os equipamentos. Houve, também, aqueles que não propiciaram a manutenção adequada aos motores de popa, pois estes têm custos de manutenção mais elevados e esses acabaram se deteriorando. Alguns pescadores que dispõem dessas embarcações aproveitam-na para alugar para pescadores esportivos, empresas, pesquisadores e turistas que necessitam desse tipo de barco. Assim, criou-se uma atividade complementar à pesca.

Há diversos outros insumos adquiridos pelos pescadores no comércio, como sacos de ráfia para se preparar armadilhas para capturar caranguejos, denominados localmente de redinha. Motores e outros utensílios para montagem do escafandro que é utilizado na pesca de ostra pela comunidade do Sítio de Cachoeira entre outros produtos adquiridos no comércio local.

Existem também produtos adquiridos com artesãos, além dos já citados, como, por exemplo, covos para capturas de peixes e ratoeiras para caranguejos, apesar do nome, esse apetrecho visa capturar esses crustáceos.

\subsubsection{PESCADORES}

Sãos os trabalhadores que vivem diretamente da explotação do estuário, baía, mar, rios, mangues, costões rochosos e arenosos. Existem pescadores que vivem exclusivamente da pesca, outros a têm como atividade principal, há aqueles que a fazem como complementar e existem as pessoas que por passarem dificuldades financeiras pescam, pois esta é uma importante fonte de proteína. RIBEIRO NETO E OLIVEIRA 
(1989) E MOREIRA JUNIOR (2008) identificaram pessoas que alternam trabalho na pesca e na sociedade envolvente, tanto no setor formal, quanto informal.

\subsubsection{PROCESSADORES}

São os que propiciam alguma transformação no pescado que pode conseqüentemente agregar valor. Isso pode ser feito pelo próprio pescador e seus familiares, por outros pescadores e famílias que adquirem pescado dos colegas para beneficiar e ampliar seus ganhos, por comerciantes que também os beneficiam e pelas indústrias de processamento do pescado. O beneficiamento mais comum é a limpeza do peixe, ou como dizem os caiçara "consertar o peixe", essa ação não agrega valor ao peixe, porém, muitos consumidores pedem que seja feita essa limpeza. Quando se faz a limpeza: do camarão, tirando-Ihe cabeça e casca; do marisco e berbigão tirando-Ihe as valvas; e do siri e caranguejo retirando-Ihes a carne da carapaça acarreta um aumento considerável do valor do pescado.

O beneficiamento do pescado pode ser realizado pelo próprio pescador e seus familiares, por pequenas processadoras de propriedade familiar que não tem registro nos órgãos governamentais, por comerciantes e indústrias especializadas, estas ainda costumam embalar as mercadorias e seguem padrões determinados pela legislação e órgãos que regulam o comércio de alimentos.

\subsubsection{COMERCIANTES}

São os que vendem o pescado no atacado e ou no varejo. Estes têm diferentes portes que vão desde aqueles que atendem o mercado local, até os que comercializam o pescado em outras regiões do país e até do exterior.

Tratar-se-á das formas no qual o pescador comercializa a produção mais adiante, no momento será discutido de forma geral as diferentes maneiras que ocorre a comercialização do pescado. 
É comum encontrar na região, pequenos comerciantes ambulantes que compram o pescado diretamente com o pescador ou que com esses mantém parceria. Podem-se citar como exemplo os vendedores de caranguejo; os que vendem porta a porta; os ambulantes que tem bicicletas adaptadas e vendem pelas ruas; as barracas de feiras e bancas de peixes que se encontram por toda a região.

Bares, restaurantes, padarias, lanchonetes, casas noturnas, peixarias, quiosques e barracas de praia que atendem diferentes classes sociais. Também são importantes comercializadores de pescado produzido localmente, que podem ser adquiridos diretamente com os pescadores ou atacadistas e atravessadores.

Os atravessadores são responsáveis por um volume considerável de pescado proveniente da pesca artesanal que é escoado para a Região Metropolitana de São Paulo - RMSP, no interior do estado e em outras localidades do Brasil. A relação entre os pescadores e atravessadores varia entre harmoniosa e conflituosa, passando por indiferente.

$\mathrm{Na}$ Baixada Santista, também, houve esse modelo de exploração do pescador, porém, como a região tem um grande mercado consumidor e está perto da RMSP, que é outro grande mercado essa exploração não se deu de forma intensa, como em outros pontos do litoral. Pescadores que necessitavam comprar apetrechos e ou embarcações podiam se endividar com atravessadores, porém, sempre havia a possibilidade de vender parte da produção para outros compradores a preços melhores, isso forçava os atravessadores a pagarem o que os pescadores achavam mais justo.

O estuário da Baixada Santista é fortemente poluído, isso era mais intenso nas décadas de 1970 e 1980 (ABESSA, 2002; CETESB, 2001), de acordo com os relatos essa poluição influenciava na qualidade do pescado, o que fazia com que esse perdesse valor e até em muitos momentos chegasse a ser inviável a venda devido à péssima qualidade. Atravessadores se especializaram em comprar a produção da pesca artesanal de Cubatão e pagavam valores muito baixos e misturavam-na em meio a lotes de peixe adquiridos dos barcos industriais e dos artesanais de áreas menos poluídas e vendiam na RMSP e no interior do Estado de São Paulo. Nesta época chegou haver dependência de 
muitos pescadores aos atravessadores que tinham essa prática, pois estes chegavam a absorver quase toda a produção local. Trabalhos como os de ABESSA (2002) e da CETESB (2001), juntamente com os depoimentos recolhidos indicam que a poluição amenizou nas décadas seguintes e, conseqüentemente, a dependência dos pescadores em relação aos atravessadores. Porém, deve-se destacar que essa prática ainda é comum na região.

Vários depoimentos indicam que os atravessadores cumprem um importante papel no escoamento da produção, pois são uma opção a mais para a venda do pescado. As diferentes possibilidades de venda do pescado propiciam ao pescador maior poder de barganha sem criar dependência dos seus compradores, salvo exceções.

Além da venda do pescado para consumo alimentar, muitos pescadores se especializaram em pescar camarão-branco (Penaeus schimitti) para ser utilizado como isca viva por pescadores esportivos, porém, essa atividade sofreu um declínio na última década devido ao fato de algumas marinas, da região, começarem a criar e ou comercializar de forma irregular um camarão exótico, o Sitopenaeus vannamei que por ser criado intensivamente tem preço de venda inferior ao camarão-branco. Assim, os pescadores esportivos preferem comprar esse camarão exótico. A criação e venda como isca viva do Sitopenaeus vannamei é proibida na região, porém, algumas marinas burlam a legalidade e criam uma situação de prejuízo para o pescador artesanal. Apesar dos órgãos de fiscalização combaterem essa prática, ela vem persistindo; o que provoca uma série de reclamações dos pescadores artesanais, já que essa atividade se torna mais um empecilho para a manutenção no modo de produção e da qualidade de vida deles.

\subsubsection{MERCADO CONSUMIDOR}

É o ultimo elo da cadeia produtiva, compõe-se pelos consumidores finais do pescado.

Segundo dados de AFONSO (1999), as cidades da Baixada Santista que se localizam entorno do estuário tinha uma população de 1.117.904 pessoas distribuídas da 
seguinte forma: Santos com 428.421 habitantes; São Vicente 267.445; Guarujá 208.818; Praia Grande 122.354 e Cubatão com 90.866 habitantes. Essa população aumenta consideravelmente nos finais de semana prolongados, no verão e nas férias escolares de julho; Segundo Gefe et al. (2004) em levantamento parcial constatou que existem 2.731 pescadores artesanais na Baixada Santista. Porém, acredita-se que esse número seja bem maior, já que o levantamento não foi concluído ainda, além disso, existem pescadores que atuam na ilegalidade e alternam períodos de trabalho na sociedade envolvente com a pesca, constatado em RIBEIRO NETO E OLIVEIRA (1989), MOREIRA JUNIOR (2008).

Além da população residente e flutuante da Baixada Santista, esta se encontra próxima RMSP que absorve grande quantidade de pescado, pois muito é comercializado diretamente, por meio da ação de pescadores, dos atravessadores, atacadista e dos comerciantes.

\subsection{A INSERÇÃO DO PESCADOR ARTESANAL NA CADEIA PRODUTIVA}

A inserção do pescador artesanal, sua família e a comunidade na cadeia produtiva do pescado é assunto de grande importância para o entendimento das dinâmicas sociais e econômicas dessas comunidades, pois é uma parte fundamental no modo de produção, já que é onde o produto da pesca se transforma em mercadoria.

O pescador pode apresentar uma ou diferentes maneiras de escoar sua produção que pode permanecer a mesma, pode transformar-se e, ainda, coexistir simultaneamente ou por um período de tempo e, até mesmo, ao longo da vida. A cadeia produtiva não é estática, ocorrem variações por época do ano, tipo de recurso e oportunidades que aparecem ao longo da vida

Além do consumo e da venda as comunidades tem outras diferentes formas de escoar a produção do pescado, como, por exemplo, a doação, escambo e o mutirão. 
Pescadores costumam doar parte do pescado para outras famílias da vizinhança, sendo estas necessitadas ou não, fortalecendo laços comunitários e mantendo o princípio da reciprocidade, o que Ihes possibilitaria auxílio comunitário futuro.

O escambo apesar de na atualidade ser raro, no passado era um importante mecanismo das famílias conseguirem produtos que não produziam, ou dispunham no momento, principalmente, no tempo em que as roças faziam parte do meio de produção local e os centros urbanos e comerciais estavam distantes.

O mutirão é uma maneira de organização social no qual as pessoas se unem para fazer uma tarefa. Antigamente os mutirões eram comuns nas comunidades, porém, com as mudanças no modo de vida devido às transformações espaciais e de modos de produção e convívio essas atividades tornaram-se raras. Além das tarefas que a comunidade se organizava para realizar, havia aqueles responsáveis pela alimentação, uma parte deles pescava para as refeições do grupo.

A seguir tratar-se-á de maneira simplificada dos diferentes elos da cadeia produtiva da venda do pescado identificados, no qual os pescadores e seus familiares se inserem diretamente.

Pescador/Artesão: estes podem ser considerados fornecedores de insumos, pois a confecção de redes, embarcações e armadilhas são uma necessidade constante. Os apetrechos se deterioram com o uso e há necessidade de reparação e reposição. Existem pescadores que dominam a arte de fazer redes, armadilhas e a carpintaria, assim além da pesca mantém uma renda extra na produção desses apetrechos, alguns pescadores também produzem os seus próprios utensílios.

Pescador/Consumidor: famílias de pescadores artesanais consomem parte da produção, o pescado é um alimento sempre presente, porém não deve ser entendido como única fonte protéica. Carnes bovina, suínas e de aves também fazem parte da dieta das famílias. O que vai determinar a variedade e a quantidade dessas fontes protéicas são a preferência e a condição de adquiri-las. O próprio pescado apresenta grande diversidade de alimentos, como diferentes tipos de peixes, moluscos e crustáceos. Algumas pessoas por opção ou por estarem desempregadas, subempregadas ou ainda 
em dificuldades financeiras têm na pesca uma importante fonte de proteína, mesmo não sendo pescador profissional.

Pescador/Comerciante: muitos pescadores e seus familiares vendem a produção diretamente ao consumidor, isso ocorre principalmente em bairros mais populosos como é o caso da Vila dos Pescadores e do Sítio Conceiçãozinha, onde muitas famílias por terem outras atividades consomem o pescado produzido localmente, até mesmo por este ter preço, muitas vezes, compensador em relação à outras carnes compradas no comércio na cidade. Há também aqueles que têm um estabelecimento onde vendem diretamente para o consumidor sua produção. Isso é realizado de diferentes maneiras, como: por meio do comércio ambulante onde o pescador tem um carro ou uma bicicleta de carga especial para transportar e comercializar pescado ou ainda uma barraca para venda do pescado; alguns possuem uma venda ou peixaria para venda in natura; outros têm bares ou restaurantes. Uns são donos de pequenas marinas, em que alugam barcos, servem como guias de pesca e vendem pescado para consumo e camarão-branco como isca viva para pescadores esportivos.

Pescador/Atravessador: nos depoimentos constatou-se que havia no passado, pescadores que, além de vender sua produção, também, compravam a de colegas e revendiam para comerciantes e atacadistas na região e na Capital. Essa atividade, aparentemente, era rara nas comunidades estudadas, mas quando existia era feita em pequenas proporções e não possibilitava 0 acumulo de capital significativo. Aparentemente hoje ela não é mais realizada, provavelmente devido à falência do setor que não possibilita ao pescador ter um capital de giro. O motivo da interrupção dessa prática, pelos antigos pescadores/atravessadores, não foi identificado.

Pescador/Beneficiador: alguns pescadores beneficiam o pescado para agregar valor e diversificar os clientes. Esse beneficiamento pode ser a retirada das valvas de moluscos, filetamento de peixes, descarnar siri, limpar e salgar camarão, congelamento, entre outros. No Sítio Conceçãozinha um pescador construiu um cômodo em palafita sobre o mangue que fica atrás de sua casa para beneficiar o pescado, isto, porém, é raro. O Instituto de Pesca de São Paulo recentemente investiu em algumas capacitações para 
beneficiamento do pescado, porém, nos trabalhos de campo não se identificou resultados. O beneficiamento pode ser para a venda ao: consumidor, comerciante e atravessador. Há, também, pescadores que compram pescado para beneficiar e vender, isso costuma ocorrer quando se tem uma encomenda, superior a sua própria produção.

\subsection{RECURSOS PESQUEIROS}

Os recursos pesqueiros da pesca artesanal na região são basicamente bivalves, crustáceos e peixes. Pelo que foi levantado na revisão bibliográfica e em conversas com especialistas não há um levantamento sobre a quantidade de recurso explorado e nem a participação de cada um desses três grupos na pesca artesanal. Os trabalhos de levantamento dos recursos alvo da pesca artesanal na região foram feitos basicamente por meio de questionários estruturados e semi-estruturados, como parte complementar de algum outro estudo, que não fosse este o foco da pesquisa, assim, são limitadas as informações referentes à essa atividade extrativista.

A produção esta sempre condicionada a fatores ambientais, tanto previsíveis como as estações do ano, quanto imprevisíveis como algum fenômenos meteorológicos ou oceanográficos. Existe uma variação na disponibilidade do pescado durante 0 ano, pois há aqueles que são perenes, mas muitos têm suas safras em determinadas época, portanto, não estão disponíveis sempre.

MOREIRA JUNIOR (2008) e RIBEIRO NETO E OLIVEIRA (1989) identificaram que na região estudada existem pescadores que atuam de forma mono-específica, ou seja, direcionam seus esforços para somente um tipo de recurso, como por exemplo, os pescadores de caranguejo, camarão ou peixes e os que atuam de forma multi-específica, que são o que exploram diferentes pescados se adaptando às safras anuais, às variações ambientais e à demanda de consumo. Para RIBEIRO NETO E OLIVEIRA (1989), os pescadores multi-específicos têm ganhos maiores e, conseqüentemente, um melhor padrão de vida do que aqueles que se concentram em apenas um ou outro tipo de pesca, pois têm maior disponibilidade de recurso durante todo 0 ano e, conseqüentemente, 
mercadoria e clientes. Também, deve-se considerar sempre o fator sorte na atividade pesqueira, principalmente, quando as espécies alvo são de grande mobilidade como, por exemplo, os peixes pelágicos.

\section{CONCLUSÕES}

As comunidades de pescadores artesanais e caiçaras mantêm diferentes estratégias de escoamento da produção do pescado. O pescador pode apresentar uma ou diferentes maneiras de escoar sua produção que pode permanecer a mesma, pode transformar-se e, ainda, coexistir simultaneamente ou por um período de tempo e, até mesmo, ao longo da vida. A cadeia produtiva não é estática, ocorrem variações por época do ano, tipo de recurso e oportunidades que aparecem ao longo da vida. $O$ escoamento da produção identificado foi: consumo familiar; doação; escambo; comércio e perdas.

A produção nem sempre entra em uma lógica de mercado, pois ela assume também papéis sociais e culturais, quando é doada a membros da comunidade, trocada por outras mercadorias. Essas são práticas muito antigas no universo caiçara e da pesca e que fortalecem e mantêm determinadas relações sociais do grupo e sua identidade.

Dentro da cadeia produtiva do pescado, o pescador assume diferentes papéis, como de fornecedor de insumos, que são os artesãos; os produtores; os comerciantes atacadistas e varejistas; os beneficiadores e os atravessadores. Essas atividades são feitas dentro de universo formal e informal da economia, em que muitas vezes os pescadores se movem continuamente e até mesmo ocupando os dois espaços.

Os pescadores apresentaram grande diversidade e adaptabilidade de inserção na cadeia produtiva, mesmo sendo um segmento da sociedade muitas vezes marginalizado e descriminado, pois faltam políticas públicas para a preservação do ambiente natural, do recurso e da qualidade de vida dessa parcela da sociedade. Há, também, ausência de uma intervenção do estado para regular a cadeia produtiva do pescado de origem artesanal, já que esta se encontra dentro de uma regulamentação que foi feita para 
atender a cadeia produtiva industrial, estando tanto o pequeno produtor, quanto 0 beneficiador e o comerciante legados a marginalização.

\section{REFERÊNCIAS}

ABESSA, D. M. S. Avaliação da qualidade de sedimentos do Sistema Estuarino de Santos, SP. São Paulo. 2002. 290 p. Tese (Doutorado em Oceanografia), Instituto Oceanográfico, Universidade de São Paulo.

AFONSO, C. M. Uso e ocupação do solo na zona costeira do estado de São Paulo. São Paulo: Annablume, FAPESP. 1999.

CASTRO, A. M. G.; COBBE, R.V.; GOEDERT, W. J. Prospecção de demandas tecnológicas: manual metodológico para o SNPA. Brasília: Embrapa/DPD, 1995.

COMPANHIA ESTADUAL DE SANEAMENTO AMBIENTAL - CETESB. Relatório Sistema Estuarino de Santos e São Vicente. 2001. São Paulo: relatório técnico.

DIEGUES, A.C. Pescadores camponeses trabalhadores do mar. São Paulo: Ática. 1983.

FREITAS, S. M. de. História Oral: possibilidades e procedimentos. Humanitas/FFLCH/USP: Imprensa Oficial do Estado, São Paulo, 2002.

GEREFFI, G.; KORZENIEWICZ, M. Commodity chains and global capitalism. Westport: Greenwood Press, 1944.

GEFE, W.; AMORIM, L. F.; AMORIM, A. F. Aspectos sócio-econômicos da pesca artesanal na região da baixada Santista In: CONGRESSO BRASILEIRO DE PESQUISA AMBIENTAL E SAÚDE, 3., 2004, Santos/SP, julho.Resumo expandido...Santos.V. 1, p. 206-209.

MALDONADO, S. C. Pescadores do mar. São Paulo: Editora Ática. 1986. 
MOREIRA JUNIOR, W. A pesca artesanal no complexo estuarino da Baixada Santista $(S P)$ e sua relação com os impactos ambientais na perspectiva das comunidades locais. 2008. 345f. Dissertação (Mestrado em Pesca). Instituto de Pesca/APTA/SAA-SP. São Paulo.

MOURÃO, F. A. A. Os pescadores do litoral sul de São Paulo. Um estudo de sociologia Diferencial. 1971. Tese (Doutorado), faculdade de Filosofia Letras e Ciências Humanas, Universidade de São Paulo, São Paulo.

PETRONE, P. O povoamento antigo e a circulação. In: A Baixada Santista; aspectos geográficos. São Paulo: Editora da Universidade de São Paulo. 1965. p. 11-138.

RIBEIRO NETO, F. B. e OLIVEIRA, M. F. Estratégias de sobrevivência de comunidades litorâneas em regiões ecologicamente degradadas: o caso da Baixada Santista. São Paulo: F. Ford/IUCM/IOUSP. 1989.

SCHULTZ, G. As cadeias produtivas dos alimentos orgânicos comercializados na Feira da Agricultura Ecológica em Porto Alegre/RS: lógica de produção e/ou de distribuição.

2001. 181f. Dissertação (Mestrado em Agronegócios)-Centro de Estudos e Pesquisa em Agronegócio, UFRGS, Porto Alegre.

SILVA, L. C. de. Cadeia produtiva de Produtos Agrícolas.Boletim Técnico. $10 f$. Departamento de Engenharia Rural. Universidade federal do Espírito Santo. 2005.

SILVA SOBRINHO, C. Romagem pela terra dos Andradas. Rio de Janeiro. Sem editor. 1957.

VIERTLER, R. B. Métodos antropológicos como ferramenta para estudo em etnobiologia e etnoecologia. In: AMOROSO, M. C. de M.; MING, L. C. PEREIRA DA SILVA, S. M. Métodos de coleta e análise de dados em etnobiologia, etnoecologia e disciplinas correlatas. Rio Claro: Sociedade Brasileira de Etnobiologia e Etnoecologia/ UNESP. 2002. 


\section{Periódica Eletrânica

ZYLBERSZTAJN, D. Agribusiness: conceito, dimensões e tendências. In: FAGUNDES, M. H. (Org.). Políticas agrícolas e comércio mundial. Brasília: IPEA, 1994. p. 351-379. (Estudos de Política Agrícola, 28). 